\title{
TOWARD A SUSTAINABLE US HEALTH CARE SYSTEM: POLICY IMPLICATIONS OF MARKET JUSTICE AND SOCIAL JUSTICE
}

\author{
A. Henry ELIASSEN 1 \\ DOI: https://doi.org/10.35782/JCPP.2021.3.02
}

\begin{abstract}
The COVID-19 pandemic and current projections of rising health expenditures point to an impending sustainability crisis in US health care institutions, torn between competing demands of individualistic values (market justice) and collective values (social justice). Champions of individual responsibility are likely to favor a disease management model of health care wherein the maintenance of lucrative food, medical, and pharmaceutical industries depends in large part on the creation and reproduction of an older but sicker consumer base, with survival to old age contingent on individuals' capacity to pay for tests, treatments, and prescriptions. In contrast, proponents of community solidarity favor a health promotion model emphasizing primordial prevention - focused upstream on improvements in nutrition and in living and working conditions potentially capable of forestalling the onset of disease in the first place. In the end, health system sustainability will hinge on policy makers' readiness to recognize, and innovate in response to, deeply ingrained values of both individual responsibility and community solidarity. To foster longterm stability in health care, effective policy must strive toward meeting the following essential needs: (1) optimal population health, (2) consumer and provider satisfaction, (3) fiscally stable and affordable funding sources, and (4) replacement opportunities for jobs lost to restructuring.
\end{abstract}

Keywords: US health policy; sustainable health care; market justice; social justice; disease management; health promotion

\section{Introduction}

Starting in March 2020, repercussions of the COVID-19 pandemic - heightened demand for pandemic-related health services, together with shortages of medical resources (Emanuel et al., 2020) and widespread disruptions to economic activity and elective medical procedures (Clarke, 2020; Mendoza, Rojas, Tesar, \& Zhang, 2020) have posed unprecedented threats to the sustainability of health care institutions. Even

$1 \mathrm{PhD}$, Associate Professor of Sociology, Department of Social Sciences, University of HoustonDowntown, 1 Main Street, N1067, Houston, TX 77002-1014, USA. Tel: 713-221-2763. Fax: 713-221-8144.E-mail: eliassena@uhd.edu 
before the pandemic, the likelihood of an impending sustainability crisis was evinced by projections that US health expenditures would soon represent close to 20 percent of the gross domestic product (Keehan et al., 2020), and that the Medicare Hospital Insurance trust fund would be depleted by 2026 (Medicare Trustees, 2020). In this context, the persistence of Republican efforts to repeal or cripple the Affordable Care Act and weaken the social welfare safety net - in the face of widespread opposition from voters at risk of losing access to health care - highlights an ongoing moral dilemma in the United States.

From its beginnings, American life has found itself torn between competing demands of individualistic values (personal initiative and market justice) versus collective values (communal responsibility and social justice) (Beauchamp, 1976). The choice here is between two seemingly divergent, yet in reality intertwined, paths: do I seek out my fortune (exercise individual economic freedom, take calculated risks, and reap my due rewards); or do I look out for my family, neighbors, and community (protect the vulnerable and promote the common good)? Public health practitioners and advocates typically concentrate on ways of promoting social justice, with the understanding that health inequities will ultimately make us all sick; and yet their calls for action often fall on deaf ears. A frequent counterargument - decisive in the end for many stakeholders and policy makers who embrace the "frontier culture" perspective of "rugged individualism" (Bazzi, Fiszbein, \& Gebresilasse, 2020) - is that heavy-handed health policies and regulations restricting market forces will stifle freedom of choice and result in loss of jobs. This "frontier culture" perspective - increasingly reflected in Republican political discourse, especially since 2000 - favors self-reliance, self-interest, and opposition to governmental intervention via taxation, regulation, and social protection (Bazzi et al., 2020).

Critics of this hands-off approach warn that under the deregulation sought by free market advocates - whereby market forces are increasingly allowed free rein in manipulating health care supply and demand - the salient issue will likely become not so much "whether the economy can sustain the observed GDP elasticities of health spending for the foreseeable future, but whether the added health care used is worth its added cost in terms of the loss of the other goods and services that will be sacrificed for the sake of the added health care" (Reinhardt, Hussey, \& Anderson, 2002, p. 172). After all, resources expended on health care are no longer available for consumer spending and investment in other sectors of the economy. Sooner or later, unchecked growth in the health sector will reach a tipping point of unsustainability once expanded health services can no longer be supported by growth in productivity elsewhere. At that point, growth in the number of chronically ill people needing protracted health care services will have resulted in the population's inability to maintain levels of productive employment sufficient to support the burden of premiums, copayments, deductibles, and taxes necessary for ongoing viability of its health services. This same concern will apply regardless of the extent to which the system in question is entrepreneurial or socialistic in design, privately or publicly administered, and locally or centrally managed and controlled.

Unforeseen emergencies such as disasters and pandemics can be expected to further exacerbate the imbalance between demand for, and supply of, health goods and nonhealth goods (Clarke, 2020; Mendoza et al., 2020). As noted during the COVID-19 
pandemic, sudden spikes in demand for medical and health-related resources lead to shortages and price fluctuations (often perceived as "price gouging") with the potential to raise the cost of health goods relative to that of other commodities (Mendoza et al., 2020, pp. 9-10). At the same time, economic disruptions resulting from morbidity (inability to work, unpaid family caregiving, etc.) and mandated lockdowns (business closures, loss of revenue, etc.) lead to an overall reduction in economic activity and contraction in GDP (Clarke, 2020, p. 163; Mendoza et al., 2020, pp. 11-13). The expected net result is likelihood that - perhaps sooner rather than later - the health care sector, as a share of the overall economy, might reach a crisis point of unsustainability.

In this essay, I argue that long-term sustainability in a health care system hinges on full recognition of - and innovation in response to - deeply ingrained values of both market justice and social justice. The ongoing challenge is to find effectual ways of engaging a full array of stakeholders in the community, while fostering an elusive balance between market justice and social justice in the pursuit of desired health outcomes. I conclude that efficacious policy must strive to meet the following essential needs: (1) optimal population health, (2) consumer and provider satisfaction, (3) fiscally stable and affordable funding sources, and (4) replacement opportunities for jobs lost to restructuring.

\section{Social responsibility versus freedom of choice}

Whereas a primary goal of public health is to cultivate a healthy community through population-based policies and interventions designed to minimize harmful exposures and promote equitable access to resources (implying pursuit of social justice), the individualistic perspective that holds sway among much of the general public calls for emphasis on personal responsibility and freedom of choice unimpeded by outside regulation (implying pursuit of market justice) (Beauchamp, 1976). Wallack and Lawrence (2005, p. 567) argue that 'the first 'language' of American culture is individualism [but that a] second American language of community - rooted in egalitarianism, humanitarianism, and human interconnection - serves as the first language of public health." Our challenge today is to convey the message of social responsibility in health promotion in ways that will effectively connect with a public - and with policy makers - thoroughly steeped in the "first language" of market justice. The fundamental question demanding our continual engagement is that of why population health is important. We need to demonstrate how our interdependence calls for the well-being of everyone, not just ourselves and our own families. A key ongoing challenge is to convincingly answer market justicebased arguments that health regulations are needlessly restrictive job killers - and to set forth the benefits attainable from having a healthy population - in ways that will resonate emotionally (as well as in the abstract) with an array of different audiences.

The crux of the matter is that public health messages focused on effective ways to prevent disease and maintain good health are typically a hard sell to the general public, health care providers, and policy makers alike (Fineberg, 2013). Preventive measures such as dietary modification, getting enough exercise, and foregoing the stress relief afforded by smoking and excessive alcohol are commonly framed as onerous burdens, "simply too difficult for most people to follow and stick with" (Fuhrman, 2016, p. 9). On the 
other hand, interested parties who profit from unhealthful products and lifestyles are often successful in efforts to dismiss "nanny state" regulations as undue interference in the free marketplace (Sharfstein, 2013). Granted, prevention is deeply embedded in US folk wisdom (e.g., "a stitch in time saves nine" and "an ounce of prevention is worth a pound of cure"). Yet, as Fineberg (2013, p. 85) notes, "prevention is expected to produce a net financial return, whereas treatment is expected only to be worth its cost; and commercial interests as well as personal, religious, or cultural beliefs may conflict with disease prevention". The upshot is that, despite growing scientific knowledge about the underlying causes of preventable morbidity, despite efforts to educate the public and promote healthful living, and despite lip service paid to the clear advantages of preventive over curative care, our burden of health care cost continues to rise.

One prime example of the upstream factors contributing to this cost spiral is patterns of food consumption - which can be crucial as drivers of either health or disease over the life course (Fuhrman, 2018). A key contributor to poor health (and thus to demand for costly medical treatments) is the calorie-dense and nutritionally poor standard American diet (Grotto \& Zied, 2010), heavily promoted by food producers and marketers. The proliferation of highly profitable (and addictive) junk food (via "bliss point" manipulation of sugar, salt, and fat in processed foods) (Moss, 2013) represents a major point of contention. Data from the Global Burden of Disease 2010 Study indicate that risks related to composition of diet may now be surpassing tobacco smoking as the leading risk factors for disability and premature death in the United States (US Burden of Disease Collaborators, 2013). With Big Food, there is growing concern that we are now looking at something like a repeat of the Big Tobacco history - wherein "industry talks about the moral high ground but does not occupy it" (Brownell \& Warner, 2009, p. 260).

\section{Where is the "moral high ground"?}

It depends. The ethical basis for equitable distribution of health-related products and services presupposes a quest for equality within some space that is seen as of central value in one's particular theory of justice; "[t] he central step, then, is the specification of the space in which equality is to be sought, and the equitable accounting rules that may be followed" (Sen, 2002, pp. 659-660). Market justice focuses on individual freedom of choice; it sees health-related products and services as commodities to be offered and purchased in good faith, with each provider and investor due equitable compensation for the value they contribute. Social justice, on the other hand, focuses on optimizing health and well-being at the population level; it views health care as a public good analogous to education, with attached rights (e.g., universal access to health services) coupled with obligations (e.g., support of those services through payment of taxes).

\subsection{The market justice perspective}

From a classic market justice standpoint, as expressed by Nobel laureate Milton Friedman, in a free economy 
there is one and only one social responsibility of business: to use its resources and engage in activities designed to increase its profits so long as it stays within the rules of the game, which is to say, engages in open and free competition, without deception or fraud. Few trends could so thoroughly undermine the very foundations of our free society as the acceptance by corporate officials of a social responsibility other than to make as much money for their stockholders as possible (Friedman, 1962/1982, p. 112).

In this context, market forces of supply and demand determine what products and services will be available, and at what prices. The process is intrinsically value neutral, with no regard as to who will be helped and who will be harmed. The process is sustained by a quest for personal survival, expressed through the profit motive. This quest applies to corporate survival as well, with corporate entities being legally defined as fictitious persons. The underlying ethical principle delimits fairness as occurring only insofar as every person (whether real or fictitious) is fully entitled to the fruits of his or her own productive labor. Hence, taxation (i.e., the taking of private property for public use via governmental coercion) is theft (Rothbard, 1982/1998). This anti-statist, laissez-faire libertarian perspective provides ideological underpinning for much of today's right-wing political discourse.

\subsection{The social justice perspective}

From a social justice standpoint, British sociologist T. H. Marshall advocated for health care as a right of citizenship:

It is just as important for a society to have a healthy population as to have an educated one, so the right to bealth, like the right to education, is blended with duties. Public health is in large measure a form of public discipline, and the element of obligation spreads from environmental to personal health, from one's duty to one's neighbours to one's duty to one's dependants and one's duty to oneself. Health regulations, health visitors and bealth education are there to promote welfare by stressing a duty even more than a right, for your body is part of the national capital, and must be looked after, and sickness causes a loss of national income, in addition to being liable to spread (Marshall, 1965, p. 269).

Social justice implies the equitable distribution of costs and benefits related to a broad array of resources that serve to promote health and well-being - including education, environmental quality, and optimal nutrition - as well as access to health care. Social epidemiologist Sir Michael Marmot and colleagues argue that health inequalities ultimately stem from inequalities in society, and that action to reduce health disparities "does not require a separate bealth agenda, but action across the whole of society" (Marmot et al., 2010, p. 16). The prerequisites for social justice extend far beyond provision of equitable access to protective and restorative resources such as health care. Under the health capability approach of Sen (2002) and Ruger (2004), health policy should aim to maintain and improve people's overall capacity to achieve health, not only by meeting specific health needs but also by fostering conditions that enhance "buman agency - i.e., people's ability to [choose and] live a life they value" (Ruger, 2004, p. 1094). Indeed, full social justice demands the dismantling of institutional structures that were designed, whether explicitly or implicitly, to perpetuate socioeconomic inequality and the unearned privilege of the fortunate few. From a social justice perspective, 
no nation can be truly great if its policies systematically marginalize some members of its population so as to deny them full access to available opportunities for maximal participation in the community.

\section{Implications of market justice and social justice}

\subsection{Health promotion (from a market justice perspective)}

Since the ultimate goal of maintaining a healthy population implies a need for strategies to help people avoid risky products and services likely to trigger disease - and thereby to drastically reduce the need (and hence the demand) for health care products and services down the line - the net result is loss of potential profit, which translates into a downward spiral of job loss in affected industries.

\subsection{Disease management (from a market justice perspective)}

Meeting the ultimate goal of maintaining a profitable disease management system hinges on successfully bringing in repeat business. Marketing and lobbying strategies are designed to create and sustain an ongoing demand for profitable if risky products and services (and also for remedial services to counter the harms they cause), and to mobilize against "nanny state" efforts at regulation and control. The net result is heightened opportunity for profit and job creation in an array of growth industries engaged in both the manufacture of disease and the treatment of disease.

The maintenance of highly lucrative food, health care, and pharmaceutical industries and the jobs they provide - depends in large part on the creation and reproduction of an older but sicker population - one with survival to old age contingent to a great extent on individuals' continuing capacity to pay for needed tests, treatments, and prescriptions. The key to success is bringing in repeat business through (1) promoting those costly illnesses that are not quick killers but can be profitably managed over the long haul, and also (2) promoting the selective survival of patients most likely to come back and avail themselves repeatedly of gainful and jobs-sustaining disease management services. This business-oriented marketplace scenario likely accounts for persistent stakeholder efforts to marginalize and discredit the public health ideals of primordial prevention (Bonita, Beaglehole, \& Kjellström, 2006, pp. 103-104) which focus upstream on improvements in nutrition and in living and working conditions improvements potentially capable of forestalling the onset of disease in the first place.

\subsection{Health promotion (from a social justice perspective)}

The ultimate goal is to maintain a healthy and productive population, and thereby sharply curtail the societal cost of disease down the line. Intervention strategies are designed to incentivize and support healthful lifestyle choices at the expense of risky activities, products, and services likely to trigger disease. The key is to make the healthy choice the default choice - whether by improving living and working conditions at the 
community level (Ashe, Graff, \& Spector, 2011) or by modifying behavioral choice environments so as to favor healthier alternatives (Volpp \& Asch, 2017).

\subsection{Disease management (from a social justice perspective)}

Given a strong and comprehensive regimen of health promotion in the community, effective disease management by health care providers will play a secondary though vital role in maintaining population health. Universal access to health care based on medical need (rather than ability to pay) is an essential implication of the broadly construed principle of community solidarity underlying social justice - in sharp contrast to the actuarial fairness principle (coverage based on individual risk) favored by market justice (Stone, 1993). A stable health care system that provides need-based medical coverage for all can be sustainable if (1) its costs are bearable and equitably distributed over the entire population (i.e., on the basis of income); (2) its demands on patients, providers, and other stakeholders are tolerable by all parties; and (3) the population's overall health allows for its burden of disease to be held in check at an affordable level.

\section{Toward a sustainable health system}

Sustainability in a health care system (Fineberg [2012] prefers the alternative term health system for arrangements that go beyond provision of health care) is a dynamic construct representing the system's ability to adapt and survive in the face of changing circumstances - including demographic shifts toward an older and more diverse population, technological advances, evolving patient expectations, and fluctuations in the economy and in the political climate (Birch, Murphy, MacKenzie, \& Cumming, 2015). Essential attributes of a sustainable health system, in addition to adaptability, include acceptability to key constituents and affordability (Fineberg, 2012). A fully sustainable system would be one capable of successfully orchestrating the complex forces shaping demand, supply, and need for health care, and one with funding mechanisms sufficiently impervious to demographic and political pressures and to economic downturns.

The quest for sustainability poses a profound challenge for both market justice and social justice. Proponents of market justice will actively contest those cost control measures, whether imposed by governmental regulators or by managed care organizations, that are designed to hold expenditures in check by artificially restricting the supply (and hence profitability) of health services. Indeed, much of the focus up to now in public discourse on health care sustainability (e.g., Orszag, 2011) has centered on effective and acceptable ways of controlling health care costs. The underlying assumption seems to be that market forces have become so dominant that efforts at disease prevention are marginalized.

Proponents of social justice, on the other hand, are concerned about obtaining and maintaining adequate funding for universal sickness coverage, and for social services that foster healthy communities, in the face of economic and political uncertainty. Also at issue is the convoluted task of placing social justice on an equal footing with market 


\section{4 | Policy implications of market justice and social justice}

justice in the quest for optimum long-term health. For example, how might public health advocates effectively promote a comprehensive agenda to (1) provide a reliable, readily accessible, and affordable nutrient-dense food supply with a minimum of processing, pesticides, and pathogens; (2) protect the environment by identifying and remediating persistent sources of pollution as well as cleaning up or containing specific pollutants; and (3) mitigate causes of unnecessary biophysical and psychosocial stress in daily life - and do so in ways that are sustainable and that provide due reward to innovators?

Further, how can persuasively tailored and personalized messages help steer the public away from stubbornly entrenched defeatist notions (often promulgated or reinforced by stakeholders in the status quo)? For instance, many have been led to believe that ill health (heartburn, obesity, diabetes, hypertension, and so on) is inevitable as a to-beexpected consequence of the "good life" and that effective change is difficult or impossible to maintain. How can messages be framed so as to establish meaningful connections with a variety of audiences (e.g., workers, ethnic groups, and academics), showing how this will personally affect them and their families? What combinations of incentives, penalties, and subsidies might serve as both effective and acceptable ways to help make the healthy choice the easy choice? A complicating factor, especially in a time of deep political polarization, is that public health messages embraced by some individuals are likely to produce strong partisan backlash in others (Gollust, Barry, \& Niederdeppe, 2017). In any case, solutions arrived at through an informed process of public dialogue ahead of time are most likely to succeed (Sharfstein, 2013). But the degree of success may well hinge on simultaneously meeting the demands of both social justice and market justice.

Finally, the unintended consequences of institutional or systemic flux brought about in response to changing circumstances can become a wild card with regard to a system's long-term survival and prosperity. A prime example - often overlooked in discourse on paths to sustainability - is the problem of job loss due to technological changes, organizational restructuring, and shifts in demand for a broad array of health-related products and services. Consider, for instance, that much of the excess spending on health care in the United States relative to that in other countries can be attributed to higher administrative costs (Woolhandler, Campbell, \& Himmelstein, 2003), and that a fundamental goal of converting to a single-payer system would be to mitigate this disproportionate burden. In theory, eliminating medically superfluous tasks related to the bureaucratic complexities of a fragmented system (such as culling patients on the basis of insurance status, managing referrals for access to specialists, and billing a bewildering variety of third-party payers) should assure that a greater proportion of health care dollars will actually go toward providing health care. Yet every effort to improve efficiency by eliminating waste and otherwise reducing unnecessary expenditure will translate directly into the loss of someone's income - and those parties whose livelihood is on the line will predictably organize and lobby in concerted opposition (Reinhardt, 2012). Thus, a necessary precondition for sustainability may well be the ready availability of satisfactory new opportunities for those whose jobs or profits are sacrificed. 


\section{Essential elements of policy application: Four pillars of health care sustainability}

In the end, health system sustainability will hinge on our readiness to recognize - and innovate in response to - deeply ingrained values of both market justice and social justice. In order to approach any semblance of long-term stability, policy makers should continually strive toward meeting the following essential needs, all the while taking into full consideration the expectations and concerns reflected in both market justice and social justice: (1) optimal population health, (2) consumer and provider satisfaction, (3) fiscally stable and affordable funding sources, and (4) replacement opportunities for jobs lost to restructuring.

\subsection{Optimal population bealth}

Prerequisite to a sustainable system of health care is, first and foremost, a manageably low level of morbidity in the population being served. Health policy - and social policy in general - should be geared toward maximizing the health of the overall population, over the entire life course, so as to minimize the downstream need (and hence the demand) for medical care (i.e., for the treatment and management of disease). Achievement of this goal implies sufficient attention to the social determinants of health:

[T] he high burden of illness responsible for appalling premature loss of life arises in large part because of the conditions in which people are born, grow, live, work, and age. In their turn, poor and unequal living conditions are the consequence of poor social policies and programmes, unfair economic arrangements, and bad politics. Action on the social determinants of health must involve the whole of government, civil society and local communities, business, global fora, and international agencies. Policies and programmes must embrace all the key sectors of society not just the bealth sector (CSDH, 2008, p. 1).

\subsection{Consumer and provider satisfaction}

To facilitate more equitable and efficient delivery of health services, with less duplication and fewer onerous administrative tasks, policy makers need to seek out and be attuned to input from stakeholders in the medical encounter - including patients and their families as well as doctors and allied professionals - regarding issues such as system navigation, clinical autonomy, and obstacles to safe and effective treatment. Health care consumers typically seek ease of access to needed services, a friendly (and user-friendly) environment, excellence in professional care, security, reasonable cost, and quality in personal interactions. Major factors influencing physician satisfaction include freedom to exercise best clinical judgment in delivery of quality care, usability and efficiency of electronic health record systems, income stability and fairness, and relief from burdensome administrative rules and requirements (Friedberg et al., 2013). 


\subsection{Fiscally stable and affordable funding sources}

A sustainable health care system will need to be immunized in some way against threats to its financial stability resulting from short-term fluctuations in the political climate and in the economy. Policy makers should consider an extension and adaptation of the current Medicare trust funds (Medicare Trustees, 2020), financing the system through a truly progressive payroll tax with no earnings cap, and with provision for periodic tax rate adjustments based on long-term changes in benefits paid out. Other promising initiatives might include measures such as shifting Net Investment Income Tax revenues (collected from high earners) out of the general fund and into the health care system trust fund, and increasing the payroll tax surcharge for those with annual incomes exceeding \$1 million per year (Cutler, Frank, Gruber, \& Newhouse, 2020).

\subsection{Replacement opportunities for jobs lost to restructuring}

From a market justice standpoint, the elimination of jobs made obsolete by structural change can always be looked upon as opening new doors for entrepreneurial innovation. For example, today's rapid expansion of telemedicine, precipitously triggered in response to the COVID-19 pandemic (Bashshur, Doarn, Frenk, Kvedar, \& Woolliscroft, 2020), can be viewed as presenting ample opportunities for the retraining of displaced administrative personnel - conceivably to fill new positions in growth enterprises such as medical app development and technological/logistic support for electronic patient-provider communications. To expedite such transitions, lawmakers and regulators might (within a context of adequate protections for safety and privacy) be well advised to consider setting aside or relaxing unneeded bureaucratic rules and regulations in the interest of enhanced flexibility and adaptability.

\section{Conclusion}

In summary, "The United States is, and will likely remain, a thoroughly marketbased society. Both individual and cooperative effort in addition to innovative enterprise will continue to be valued and rewarded" (Eliassen, 2013, p. 20). Our ongoing challenge, then, is to find effective ways of engaging a full array of stakeholders in the community, with the goal of finding and maintaining an elusive balance between market justice and social justice in our common pursuit of optimum long-term health. Public health messaging in support of community-based efforts like medically tailored meal interventions (Berkowitz et al., 2019) and public-private partnerships to encourage production and consumption of more healthful foods - such as via subsidies and doctors' prescriptions for fruits and vegetables (Lee et al., 2019) - can portend notable victories for both 
social justice and market justice. After all, keeping the nation's population healthier promises not only to ensure a more stable and sustainable health care system, but also to foster that stronger base of workers and consumers essential to supporting widespread prosperity and job creation in a profitable and thriving economy.

\section{Acknowledgement}

An earlier version of this article was presented at the 66th annual meeting of the Society for the Study of Social Problems in Seattle, Washington, on August 19, 2016.

\section{Funding}

The author received no financial support for the research, authorship, and/or publication of this article.

\section{Declaration of conflicting interests}

The author declares no conflicting interests.

\section{References}

Ashe, M., Graff, S., \& Spector, C. (2011). Changing places: Policies to make a healthy choice the easy choice. Public Health, 125(12), 889-895. https://doi.org/10.1016/ j.puhe.2011.04.010

Bashshur, R., Doarn, C. R., Frenk, J. M., Kvedar, J. C., \& Woolliscroft, J. O. (2020). Telemedicine and the COVID-19 pandemic, lessons for the future. Telemedicine and $\mathrm{e}-$ Health, 26(5), 571-573. https://doi.org/10.1089/tmj.2020.29040.rb

Bazzi, S., Fiszbein, M., \& Gebresilasse, M. (2020). Frontier culture: The roots and persistence of "rugged individualism" in the United States. Econometrica, 88(6), 2329_ 2368. https://doi.org/10.3982/ECTA16484

Beauchamp, D. E. (1976). Public health as social justice. Inquiry, 13(1), 3-14.

Berkowitz, S. A., Terranova, J., Randall, L., Cranston, K., Waters, D. B., \& Hsu, J. (2019). Association between receipt of a medically tailored meal program and health care use. JAMA Internal Medicine, 179(6), 786-793. https://doi.org/10.1001/ jamainternmed.2019.0198

Birch, S., Murphy, G. T., MacKenzie, A., \& Cumming, J. (2015). In place of fear: Aligning health care planning with system objectives to achieve financial sustainability. Journal 
28 Policy implications of market justice and social justice

of Health Services Research \& Policy, 20(2), 109-114. https://doi.org/10.1177/ 1355819614562053

Bonita, R., Beaglehole, R., \& Kjellström, T. (2006). Basic epidemiology (2nd ed.). Geneva, Switzerland: World Health Organization. Retrieved from https://apps.who.int/iris/ bitstream/handle/10665/43541/9241547073_eng.pdf

Brownell, K. D., \& Warner, K. E. (2009). The perils of ignoring history: Big Tobacco played dirty and millions died. How similar is Big Food? Milbank. Quarterly, 87(1), 259-294. https://doi.org/10.1111/j.1468-0009.2009.00555.x

Clarke, L. (2020). An introduction to economic studies, health emergencies, and COVID-19. Journal of Evidence-Based Medicine, 13(2), 161-167. https://doi.org/10.1111/jebm.12395

CSDH. (2008). Closing the gap in a generation: Health equity through action on the social determinants of bealth (Final Report of the Commission on Social Determinants of Health). Geneva, Switzerland: World Health Organization. Retrieved from https://www.who.int/ social_determinants/final_report/csdh_finalreport_2008.pdf

Cutler, D. M., Frank, R. G., Gruber, J., \& Newhouse, J. P. (2020, June 10). Strengthening the Medicare Trust Fund in the era of COVID-19 [Health Affairs Blog post]. Retrieved from https://www.healthaffairs.org/do/10.1377/hblog20200608.322412/full/

Eliassen, A. H. (2013). The usefulness of health disparity: Stumbling blocks in the path to social equity. Journal of Community Positive Practices, 13(1), 3-25. Retrieved from http://jppc.ro/en/index.php/jppc/article/view/167/146

Emanuel, E. J., Persad, G., Upshur, R., Thorne, B., Parker, M., Glickman, A., Phillips, J. P. (2020). Fair allocation of scarce medical resources in the time of Covid-19. New England Journal of Medicine, 382(21), 2049-2055. https://doi.org/10.1056/NEJMsb2005114

Fineberg, H. V. (2012). A successful and sustainable health system - how to get there from here. New England Journal of Medicine, 366(11), 1020-1027. https://doi.org/10.1056/ NEJMsa1114777

Fineberg, H. V. (2013). The paradox of disease prevention: Celebrated in principle, resisted in practice. JAMA, 310(1), 85-90. https://doi.org/10.1001/jama.2013.7518

Friedberg, M. W., Chen, P. G., Van Busum, K. R., Aunon, F., Pham, C., Caloyeras, J. P., Tutty, M. (2013). Factors affecting physician professional satisfaction and their implications for patient care, health systems, and health policy. Santa Monica, CA: RAND Corporation. Retrieved from https://www.rand.org/pubs/research_reports/RR439.html

Friedman, M. (1982). Capitalism and freedom. Chicago, IL: University of Chicago Press. (Original work published 1962)

Fuhrman, J. (2016). The end of heart disease. New York, NY: HarperOne.

Fuhrman, J. (2018). The hidden dangers of fast and processed food. American Journal of Lifestyle Medicine, 12(5), 375-381. https://doi.org/10.1177/1559827618766483 
Gollust, S. E., Barry, C. L., \& Niederdeppe, J. (2017). Partisan responses to public health messages: Motivated reasoning and sugary drink taxes. Journal of Health Politics, Policy and Law, 42(6), 1005-1037. https://doi.org/10.1215/03616878-4193606

Grotto, D., \& Zied, E. (2010). The standard American diet and its relationship to the health status of Americans. Nutrition in Clinical Practice, 25(6), 603-612. https://doi.org/10.1177/0884533610386234

Keehan, S. P., Cuckler, G. A., Poisal, J. A., Sisko, A. M., Smith, S. D., Madison, A. J., Hardesty, J. C. (2020). National health expenditure projections, 2019-28: Expected rebound in prices drives rising spending growth. Health Affairs, 39(4), 704-714. https://doi.org/10.1377/hlthaff.2020.00094

Lee, Y., Mozaffarian, D., Sy, S., Huang, Y., Liu, J., Wilde, P. E., Micha, R. (2019). Costeffectiveness of financial incentives for improving diet and health through Medicare and Medicaid: A microsimulation study. PLoS Medicine, 16(3), e1002761. https://doi.org/10.1371/journal.pmed.1002761

Marmot, M., Allen, J., Goldblatt, P., Boyce, T., McNeish, D., Grady, M., \& Geddes, I. (2010). Fair society, healthy lives: Strategic review of health inequalities in England post-2010 (the Marmot review). London, England: The Marmot Review Team. Retrieved from http://www.instituteofhealthequity.org/resources-reports/fair-society-healthy-livesthe-marmot-review/ fair-society-healthy-lives-full-report-pdf.pdf

Marshall, T. H. (1965). The right to welfare. Sociological Review, 13(3), 261-272. https://doi.org/10.1111/j.1467-954X.1965.tb01140.x

Medicare Trustees. (2020). 2020 annual report of the boards of trustees of the Federal Hospital Insurance and Federal Supplementary Medical Insurance trust funds. Baltimore, MD: Centers for Medicare and Medicaid Services. Retrieved from https://www.cms.gov/ files/document/2020-medicare-trustees-report.pdf

Mendoza, E. G., Rojas, E. I., Tesar, L. L., \& Zhang, J. (2020). A macroeconomic model of bealthcare saturation, inequality and the output-pandemia tradeoff (NBER Working Paper no. 28247). Cambridge, MA: National Bureau of Economic Research. Retrieved from https://www.nber.org/system/files/working_papers/w28247/w28247.pdf

Moss, M. (2013, February 20). The extraordinary science of addictive junk food. New York Times Magazine. Retrieved from https://www.nytimes.com/2013/02/24/magazine/ the-extraordinary-science-of-junk-food.html

Orszag, P. R. (2011). How health care can save or sink America: The case for reform and fiscal sustainability. Foreign Affairs, 90(4), 42-56.

Reinhardt, U. (2012). Divide et impera: Protecting the growth of health care incomes (costs). Health Economics, 21(1), 41-54. https://doi.org/10.1002/hec.1813

Reinhardt, U. E., Hussey, P. S., \& Anderson, G. F. (2002). Cross-national comparisons of health systems using OECD data, 1999. Health Affairs, 21(3), 169-181. https://doi.org/10.1377/hlthaff.21.3.169 
30 | Policy implications of market justice and social justice

Rothbard, M. N. (1998). The ethics of liberty. New York, NY: New York University Press. (Original work published 1982)

Ruger, J. P. (2004). Ethics of the social determinants of health. The Lancet, 364(9439), 10921097. https://doi.org/10.1016/S0140-6736(04)17067-0

Sen, A. (2002). Why health equity? Health Economics, 11(8), 659-666. https://doi.org/ 10.1002/hec.762

Sharfstein, J. M. (2013). Public health regulation as a public process. JAMA Forum. Retrieved from https://jamanetwork.com/channels/health-forum/fullarticle/2760198

Stone, D. A. (1993). The struggle for the soul of health insurance. Journal of Health Politics, Policy and Law, 18(2), 287-317. https:/ / doi.org/10.1215/03616878-18-2-287

US Burden of Disease Collaborators. (2013). The state of US health, 1990-2010: Burden of diseases, injuries, and risk factors. $J A M A, 310(6), 591-608$. https://doi.org/ 10.1001/jama.2013.13805

Volpp, K. G., \& Asch, D. A. (2017). Make the healthy choice the easy choice: Using behavioral economics to advance a culture of health. QJM: An International Journal of Medicine, 110(5), 271-275. https://doi.org/10.1093/qjmed/hcw190

Wallack, L., \& Lawrence, R. (2005). Talking about public health: Developing America's "second language." American Journal of Public Health, 95(4), 567-570. https://doi.org/10.2105/AJPH.2004.043844

Woolhandler, S., Campbell, T., \& Himmelstein, D. U. (2003). Costs of health care administration in the United States and Canada. New England Journal of Medicine, 349(8), 768-775. https://doi.org/10.1056/NEJMsa022033 